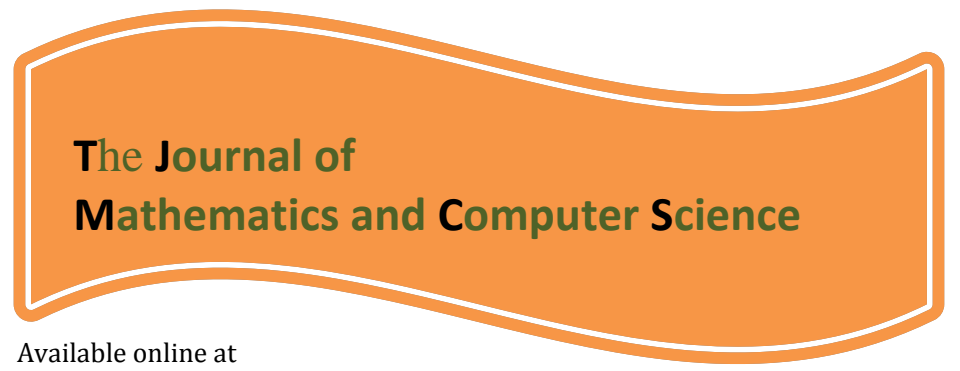

http://www.TJMCS.com

The Journal of Mathematics and Computer Science Vol .2 No.3 (2011) 475-482

\title{
ON THE FUZZY METRIC SPACES
}

\author{
G. A. Afrouzi ${ }^{1}$, S. Shakeri², S. H. Rasouli ${ }^{3}$ \\ afrouzi@umz.ac.ir \\ s.shakeri@iauamol.ac.ir \\ s.h.rasouli@nit.ac.ir
}

Received: July 2010, Revised: October 2010

Online Publication: January 2011

\begin{abstract}
In this paper we define complete fuzzy metric space and proved that a fuzzy topologically complete subset of a fuzzy metric space is a $G_{\delta}$ set and prove that a converse of Sierpinsky theorem by showing that any $G_{\delta}$ set in a complete metric space is a topologically complete fuzzy metrizable space (Alexandroff Theorem).
\end{abstract}

Keywords: fuzzy metric spaces, complete fuzzy metrizable space, Alexandroff theorem

\section{Introduction}

The theory of fuzzy sets was introduced by L.Zadeh in 1965 [12]. After the pioneering work of Zadeh, there has been a great effort to obtain fuzzy analogues of classical theories. Among other fields, a progressive developments is made in the field of fuzzy topology. One

\footnotetext{
' Department of Mathematics, Faculty of Basic Sciences, Mazandaran University, Babolsar, Iran

${ }^{2}$ Department of Mathematics, Islamic Azad University - Aytollah Amoli Branch, Amol, Iran

${ }^{3}$ Department of Mathematics, Faculty of Basic science, Babol Noshirvani University of Technology, Babol, Iran.
} 
of the most important problems in fuzzy topology is to obtain an appropriate concept of fuzzy metric space. This problem has been investigated by many authors from different points of view. In particular, George and Veeramani [2] have introduced and studied a notion of fuzzy metric space. Furthermore, the class of topological spaces that are fuzzy metrizable agrees with the class of metrizable- topological spaces (see[2] and [4]). This result permits Gregori and Romaguera to restate some classical theorems on metric completeness and metric (pre) compactness in the realm of fuzzy metric spaces [4] , [5] and [6].

In this paper we consider modified fuzzy metric space introduced by George and Veeramani [2], [3]. In [1], we proved that a fuzzy topologically complete subset of a fuzzy metric space is a $G_{\delta}$ set (Sierpinsky Theorem). In this paper we prove a converse of Sierpinsky theorem by showing that any $G_{\delta}$ set in a complete metric space is a topologically complete fuzzy metrizable space (Alexandroff Theorem).

Definition 1.1. A binary operation $*:[0,1] \times[0,1] \rightarrow[0,1]$ is a continuous t-norm if it satisfies the following conditions.

(1) * is associative and commutative,

$(2) *$ is continuous,

(3) $\mathrm{a} * 1=$ a for all $\mathrm{a} \in[0,1]$,

(4) $a * b \leq c * d$ whenever $a \leq c$ and $b \leq d$, for each

a, b, c, d $\in[0,1]$.

Two typical examples of continuous $\mathrm{t}$-norm are $\mathrm{a}^{*} \mathrm{~b}=\mathrm{ab}$ and $\mathrm{a}^{*} \mathrm{~b}=\min (\mathrm{a}, \mathrm{b})$.

The concept of fuzzy metric space is defined by George and Veeramani as follows [2].

Definition 1.2. A 3-tuple $\left(X, M,{ }^{*}\right)$ is called a fuzzy metric space if $X$ is an arbitary (non -empty) set, ${ }^{*}$ is a continuous $\mathrm{t}$-norm , and $\mathrm{M}$ is a fuzzy set on $X^{2} \times(0, \infty)$, satisfying the following conditions for each $x, y, z \in X$ and $t, s>0$,

(1) $M(x, y, t)>0$,

(2) $M(x, y, t)=1$ if and only if $x=y$,

(3) $M(x, y, t)=M(y, x, t)$,

(4) $(x, y, t) * M(y, z, s) \leq M(x, z, t+s)$

(5) $M(x, y,):.(0, \infty) \rightarrow[0,1]$ is continuous.

Let $\left(\mathrm{X}, \mathrm{M},{ }^{*}\right)$ be a fuzzy metric space. For $\mathrm{t}>0$, the open ball $\mathrm{B}(\mathrm{x}, \mathrm{r}, \mathrm{t})$ with center $x \in X$ and radius 
$0<\mathrm{r}<1$ is defined by

$\mathrm{B}(\mathrm{x}, \mathrm{r}, \mathrm{t})=\{y \in X: M(x, y, t)>1-r\}$.

Let $\left(\mathrm{X}, \mathrm{M},{ }^{*}\right)$ be a fuzzy metric space. Let $\tau$ be the set of all $A \subset X$ with $x \in A$ if and only if there exist $\mathrm{t}>0$ and $0<\mathrm{r}<1$ such that $\mathrm{B}(\mathrm{x}, \mathrm{r}, \mathrm{t}) \subset \mathrm{A}$. Then $\tau$ is a topology on $\mathrm{X}$ (induced by the fuzzy metric M). This topology is Hausdorff and first countable. A sequence $\left\{X_{n}\right\}$ in $X$ converges to $x$ if and only if

$\mathrm{M}\left(\mathrm{x}_{\mathrm{n}}, \mathrm{x}, \mathrm{t}\right) \rightarrow 1$ as $\mathrm{n} \rightarrow \infty$, for each $\mathrm{t}>0$. It is called a Cauchy sequence if for each $0<\varepsilon<1$ and $\mathrm{t}>0$, there exits $n_{0} \in \mathrm{N}$ such that

$\mathrm{M}\left(\mathrm{x}_{\mathrm{n}}, \mathrm{x}_{\mathrm{m}}, \mathrm{t}\right)>1-\varepsilon$ for each $\mathrm{n}, \mathrm{m} \geq n_{0}$. The fuzzy

metric space $\left(X, M,{ }^{*}\right)$ is said to be complete if every Cauchy sequence is convergent. A subset A of $X$ is said to be F-bounded if there exists $t>0$ and $0<r<1$ such that $M(x, y, t)>1-r$ for all $\mathrm{x}, \mathrm{y} \in \mathrm{A}$.

Theorem 1.3. In a fuzzy metric space every compact set is closed and F-bounded.

Theorem 1.4. In a fuzzy metric space every compact set is complete.

Corollary 1.5. Every closed subset of a complete fuzzy metric space is complete.

\section{Main Result}

Lemma 2.1. Let $\left(\mathrm{X}, \mathrm{M},{ }^{*}\right)$ be a fuzzy metric space and let $\lambda \in[0,1)$ then there exists a fuzzy metric $\mathrm{m}$ on $X$ such that $m(x, y, t) \geq \lambda$, for each $x, y \in X$ and $t>0$ and $m$ and $M$ induce the same topology on $X$. Proof. We define $m(x, y, t)=\max \{\lambda, M(x, y, t)\}$. We claim that $m$ is fuzzy metric on $X$. The properties of (1), (2) , (3) and (5) are immediate from the definition. For triangle inequality, suppose that $x, y, z$ $\in \mathrm{X}$ and $\mathrm{t}, \mathrm{s}>0$. Then

$\mathrm{m}(\mathrm{x}, \mathrm{z}, \mathrm{t}+\mathrm{s}) \geq \lambda$ and so $\mathrm{m}(\mathrm{x}, \mathrm{z}, \mathrm{t}+\mathrm{s}) \geq \mathrm{m}(\mathrm{x}, \mathrm{y}, \mathrm{t}) * \mathrm{~m}(\mathrm{y} . \mathrm{z} . \mathrm{s})$ when either $\mathrm{m}(\mathrm{x}, \mathrm{y}, \mathrm{t})=\lambda$ or $\mathrm{m}(\mathrm{y}, \mathrm{z}, \mathrm{s})=\lambda$. The only remaining case is when $\mathrm{m}(\mathrm{x}, \mathrm{y}, \mathrm{t})=\mathrm{M}(\mathrm{x}, \mathrm{y}, \mathrm{t})>\lambda$ and $\mathrm{m}(\mathrm{y}, \mathrm{z}, \mathrm{s})=\mathrm{M}(\mathrm{y}, \mathrm{z}, \mathrm{s})>\lambda$. But $\mathrm{M}(\mathrm{x}, \mathrm{z}, \mathrm{t}+\mathrm{s}) \geq$ $M(x, y, t) * M(y, z, s)$ and $m(x, z, t+s) \geq M(x, z, t+s)$ and so $\mathrm{m}(\mathrm{x}, \mathrm{z}, \mathrm{t}+\mathrm{s}) \geq \mathrm{M}(\mathrm{x}, \mathrm{z}, \mathrm{t}+\mathrm{s})$ and so $m(x, z, t+s) \geq m(x, y, t) * m(y, z, s)$. Thus $m$ is a fuzzy metric on $X$. It only remains to show that the topology induced by $\mathrm{m}$ is the same as that induced by M. But we have $\mathrm{m}\left(\mathrm{x}_{\mathrm{n}}, \mathrm{x}, \mathrm{t}\right) \rightarrow 1$ if and only if $\left\{\lambda, M\left(x_{n}, x, t\right)\right\} \rightarrow 1$ if and only if $\mathrm{M}\left(\mathrm{x}_{\mathrm{n}}, \mathrm{x}, \mathrm{t}\right) \rightarrow 1$, for each $\mathrm{t}>0$, and we are done.

The fuzzy metric $m$ in above lemma is said to be bounded by $\lambda$.

Definition 2.2. Let $\left(\mathrm{X}, \mathrm{M},{ }^{*}\right)$ be a fuzzy metric space, $\mathrm{X} \in \mathrm{X}$ and $\phi \neq A \subseteq X$. 
We define

$D(x, A, t)=\sup \{M(x, y, t): y \in A\}(t>0)$.

Note that $D(x, A, t)$ is a degree of closeness of $x$ to $A$ at $t$.

Definition 2.3. A topological space is called a (topologically complete) fuzzy metrizable space if there exists a (topologically complete) fuzzy metric inducing the given topology on it.

Example . Let $\mathrm{X}=(0,1]$. The fuzzy metric space $\left(\mathrm{X}, \mathrm{M}\right.$, .) where $\mathrm{M}(\mathrm{x}, \mathrm{y}, \mathrm{t})=\frac{t}{t+|x-y|}$ (standard fuzzy metric, see[2]) is not complete because the Cauchy sequence $\{1 / n\}$ in this space is not convergent. Now, if we consider triple $(\mathrm{X}, \mathrm{m},$.$) where m(x, y, t)=\frac{t}{t+|x-y|+\left|\frac{1}{x}-\frac{1}{y}\right|}$. It is straightforward to show that $(\mathrm{X}, \mathrm{m},$.$) is a fuzzy metric space, and that is complete. Since, \mathrm{x}_{\mathrm{n}}$ tend to $\mathrm{x}$ with respect to fuzzy metric $\mathrm{M}$ if and only if $\left|x_{n}-x\right| \rightarrow 0$ if and only if $\mathrm{x}_{\mathrm{n}}$ tend to $\mathrm{x}$ with respect to fuzzy metric $\mathrm{m}$, then $\mathrm{M}$ and $\mathrm{m}$ are equivalent fuzzy metrics. Hence the fuzzy metric space $(\mathrm{X}, \mathrm{M},$.$) is topologically complete fuzzy metrizable.$

Lemma 2.4. Fuzzy metrizability is preserved under countable Cartesian product.

Proof. Without loss of generality we may assume that the index set is $\mathrm{N}$ Let $\left\{\left(X_{n}, m_{n}, *\right): n \in N\right\}$ be a collection of fuzzy metrizable spaces. Let $\tau_{n}$ be the topology induced by $\mathrm{m}_{\mathrm{n}}$ on $\mathrm{X}_{\mathrm{n}}$ for $\mathrm{n} \in \mathrm{N}$ and let $(\mathrm{X}, \tau)$ be the Cartesian product of $\left\{\left(X_{n}, \tau_{n}\right): n \in N\right\}$ with product topology. We have to prove that there is a fuzzy metric $\mathrm{m}$ on $\mathrm{X}$ which induces the topology $\tau$. By the above lemma, we may suppose that $\mathrm{m}_{\mathrm{n}}$ is bounded by $1-\varepsilon^{(n)},\left(\varepsilon^{(n)}=\right.$ i.e.

$\mathrm{m}_{\mathrm{n}}\left(\mathrm{x}_{\mathrm{n}}, \mathrm{y}_{\mathrm{n}}, \mathrm{t}\right)=\max \left\{1-\varepsilon^{(n)}, M\left(x_{n}, y_{n}, t\right)\right\}$.

Ponints of $X=\prod_{n \in N} X_{n}$ are denoted as

sequences $x=\left\{x_{n}\right\}$ with $x_{n} \in X_{n}$ for $n \in N$. Define $\mathrm{m}(\mathrm{x}, \mathrm{y}, \mathrm{t})=\prod_{n=1}^{\infty} \mathrm{m}_{\mathrm{n}}\left(\mathrm{x}_{\mathrm{n}}, \mathrm{y}_{\mathrm{n}}, \mathrm{t}\right)$, for each $\mathrm{x}, \mathrm{y} \in \mathrm{X}$ and $\mathrm{t}>0,\left(\prod_{n=1}^{m} a_{n}=a_{1} * a_{2} * \ldots a_{m}\right)$.

First note that $\mathrm{m}$ is well defined since $a_{i}=\prod_{n=1}^{i}\left(1-\varepsilon^{(n)}\right)$ is decreasing and bounded then converges to $\alpha \in(0,1)$. Also $\mathrm{m}$ is a fuzzy metric on $\mathrm{X}$ because each $\mathrm{m}_{\mathrm{n}}$ is a fuzzy metric. Let $\mathrm{u}$ be the topology induced by fuzzy metric m. We claim that $u$ coincides with $\tau$. If $G \in u$ and $x=\left\{x_{n}\right\} \in G$, then there exists $0<\mathrm{r}<1$ and $\mathrm{t}>0$ such that

$\mathrm{B}(\mathrm{x}, \mathrm{r}, \mathrm{t}) \subset \mathrm{G}$. For each $0<\mathrm{r}<1$, we can find a sequence $\left\{\delta_{n}\right\}$ in $(0,1)$ and a positive integer $\mathrm{N}_{0}$ such that.

$$
\prod_{n=1}^{N_{0}}\left(1-\delta_{n}\right) * \prod_{n=N_{0}+1}^{\infty}\left(1-\varepsilon^{(n)}\right)>1-r
$$


For each $\mathrm{n}=1,2, \ldots, \mathrm{N}_{0}$, let $V_{n}=B\left(x_{n}, \delta_{n}, t\right)$, where the ball is with respect to fuzzy metric $\mathrm{m}_{\mathrm{n}}$. Let $\mathrm{V}_{\mathrm{n}}=\mathrm{X}_{\mathrm{n}}$ for

$\mathrm{n}>\mathrm{N}_{0}$. Put $V=\prod_{n \in N} V_{n}$, then $x \in V$ and $\mathrm{V}$ is an open set in the product topology $\tau$ on $\mathrm{X}$. Furthermore $V \subset B(x, r, t)$, since for each $y \in V$

$$
\begin{aligned}
\mathrm{m}(\mathrm{x}, \mathrm{y}, \mathrm{t}) & =\prod_{\mathrm{n}=1}^{\infty} \mathrm{m}_{\mathrm{n}}\left(\mathrm{x}_{\mathrm{n}}, \mathrm{y}_{\mathrm{n}}, \mathrm{t}\right) \\
& =\prod_{n=1}^{N_{0}} m_{n}\left(x_{n}, y_{n}, t\right) * \prod_{n=N_{0}+1}^{\infty} m_{n}\left(x_{n}, y_{n}, t\right) \\
& \geq \prod_{n=1}^{N_{0}}\left(1-\delta_{n}\right) * \prod_{n=N_{0}+1}^{\infty}\left(1-\varepsilon^{(n)}\right) \\
& >1-r .
\end{aligned}
$$

Hence $V \subset B(x, r, t) \subset G$. Therefore $\mathrm{G}$ is open in the product topology. Conversely suppose $\mathrm{G}$ is open in the product topology and let $x=\left\{x_{n}\right\} \in G$. choose a standard basic open set $V$ such that $x \in V$ and $V \subset G$. Let $V=\prod_{n \in N} V_{n}$, where each $\mathrm{V}_{\mathrm{n}}$ is open in $\mathrm{X}_{\mathrm{n}}$ and $\mathrm{V}_{\mathrm{n}}=\mathrm{X}_{\mathrm{n}}$ for all $\mathrm{n}>\mathrm{N}_{0}$. For $\mathrm{n}=1,2$, $\ldots, \mathrm{N}_{0}$,

let $\mathrm{r}_{\mathrm{n}}=\mathrm{D}_{\mathrm{n}}\left(\mathrm{x}_{\mathrm{n}}, \mathrm{X}_{\mathrm{n}}-\mathrm{V}_{\mathrm{n}}, \mathrm{t}\right)$, if $X_{n} \neq V_{n}$, and

$r_{n}=\varepsilon^{(n)}$,otherwise. Let $r=\min \left\{r_{1}, r_{2}, \ldots, r_{N_{0}}\right\}$. We claim that

$B(x, r, t) \subset V$. If $y=\left\{y_{n}\right\} \in B(x, r, t)$, then

$m(x, y, t)=\prod_{n=1}^{\infty} m_{n}\left(x_{n}, y_{n}, t\right)>1-\mathrm{r}$ and

so $m_{n}\left(x_{n}, y_{n}, t\right)>1-r \geq 1-r_{n}$ for each $\mathrm{n}=1,2, \ldots, \mathrm{N}_{0}$. Then $y_{n} \in V_{n}$, for $\mathrm{n}=1,2, \ldots, \mathrm{N}_{0}$. Also for $\mathrm{n}>\mathrm{N}_{0}$, $y_{n} \in V_{n}=X_{n}$. Hence $y \in V$ and so $B(x, r, t) \subset V \subset G$. Therefore $\mathrm{G}$ is open with respect to the fuzzy metric topology and $r \subset u$. Hence $r$ and u coincide.

Theorem 2.5. An open subspace of a complete fuzzy metrizable space is a complete fuzzy metrizable space.

Proof. Let $\left(X, M,{ }^{*}\right)$ be a complete fuzzy metric space and $G$ an open subspace of $X$. If the restiction of $\mathrm{M}$ to $\mathrm{G}$ is not complere we can replace $\mathrm{M}$ on $\mathrm{G}$ by othere metric as follows. Define $f: G \times(0, \infty) \rightarrow R^{+}$by

$\mathrm{f}(\mathrm{x}, \mathrm{t})=\frac{1}{1-D(x, X-G, t)}$

( $\mathrm{f}$ is undefined if $\mathrm{X}-\mathrm{G}$ is empty, but then there is nothing to prove.) Fix an arbitary $\mathrm{s}>0$ and for $x, y \in \mathrm{G}$ define.

$m(x, y, t)=M(x, y, t) * M(f(x, s), f(y, s), t)$, 
for each $t>0$. We claim that $m$ is fuzzy metric on G. The properties (1), (2), (3) and (5) are immediate from the definition. For triangle inequality, suppose that $x, y, z \in G$ and $t, s, u>0$, then. $\mathrm{m}(\mathrm{x}, \mathrm{y}, \mathrm{t}) * \mathrm{~m}(\mathrm{y}, \mathrm{z}, \mathrm{u})=$

$$
=(M(x, y, t) * M(f(x, s), f(y, s), t))^{*}
$$

$(\mathrm{M}(\mathrm{y}, \mathrm{z}, \mathrm{u}) * \mathrm{M}(\mathrm{f}(\mathrm{y}, \mathrm{s}), \mathrm{f}(\mathrm{z}, \mathrm{s}), \mathrm{u}))$

$=(M(x, y, t) * M(y, z, u))^{*}(M(f(x, s), f(y, s), t) *$

$\mathrm{M}(\mathrm{f}(\mathrm{y}, \mathrm{s}), \mathrm{f}(\mathrm{z}, \mathrm{s}), \mathrm{u}))$

$\leq \mathrm{M}(\mathrm{x}, \mathrm{z}, \mathrm{t}+\mathrm{u}) * \mathrm{M}(\mathrm{f}(\mathrm{x}, \mathrm{s}), \mathrm{f}(\mathrm{z}, \mathrm{s}), \mathrm{t}+\mathrm{u})=\mathrm{m}(\mathrm{x}, \mathrm{z}, \mathrm{t}+\mathrm{u})$.

We show that $m$ and $M$ are equivalent fuzzy metrics on $G$. We do this by showing that $m\left(x_{n}, x, t\right) \rightarrow 1$ if and only if $M\left(x_{n}, x, t\right) \rightarrow 1$. Since $m(x, y, t) \leq M(x, y, t)$ for all $x, y \in G$ and $t>0, M\left(x_{n}, x, t\right) \rightarrow 1$ whenwver $m\left(x_{n}, x, t\right) \rightarrow 1$. To prove the convers, let $M\left(x_{n}, x, t\right) \rightarrow 1$, we know from [7] Proposition $1 M$ is continuous function on $\mathrm{X} \times \mathrm{X} \times(0, \infty)$, then since.

$$
\begin{aligned}
\lim _{n \rightarrow \infty} D\left(x_{n}, X-G, s\right)=\lim _{n \rightarrow \infty}\left(\sup \left\{M\left(x_{n}, y, s\right): y \in G\right\}\right) \quad \geq \lim M\left(x_{n}, y, s\right) \\
=\mathrm{M}(\mathrm{x}, \mathrm{y}, \mathrm{s})
\end{aligned}
$$

Therefore $\lim _{\mathrm{n}} \mathrm{D}\left(\mathrm{x}_{\mathrm{n}}, \mathrm{X}-\mathrm{G}, \mathrm{s}\right)>\mathrm{D}(\mathrm{x}, \mathrm{X}-\mathrm{G}, \mathrm{s})$. On the other hand, there exists a $y_{0} \in X-G$ and $n_{0} \in \mathrm{N}$ such that for every $n \geq n_{0}$ we have.

$$
D\left(x_{n}, X-G, s\right) *\left(1-\frac{1}{n}\right) \leq M\left(x_{n}, y_{0}, s\right) \text {. }
$$

Then

$\lim _{\mathrm{n}} \mathrm{D}\left(\mathrm{x}_{\mathrm{n}}, \mathrm{X}-\mathrm{G}, \mathrm{s}\right) \leq M\left(x, y_{0}, s\right) \leq \operatorname{Sup}\{M(x, y, s): y \in X-G\}=\mathrm{D}(\mathrm{x}, \mathrm{X}-\mathrm{G}, \mathrm{s})$.

Therefore

$\lim _{n}\left(x_{n}, X-G, s\right)=D(x, X-G, s)$.

This implies

$\mathrm{M}\left(\mathrm{f}\left(\mathrm{x}_{\mathrm{n}}, \mathrm{s}\right), \mathrm{f}(\mathrm{x}, \mathrm{s}), \mathrm{t}\right) \rightarrow 1$.

Hence $m\left(x_{n}, x, t\right) \rightarrow 1$. Therefore $\mathrm{m}$ and $\mathrm{M}$ are equivalent. Next we show that $\mathrm{m}$ is a complete fuzzy metric. Suppose that $\left\{\mathrm{x}_{\mathrm{n}}\right\}$ is a Cauchy sequence in $\mathrm{G}$ with respect to $\mathrm{m}$. Since for each $\mathrm{m}, \mathrm{n} \in \mathrm{N}$ and t>0 $m\left(x_{m}, x_{n}, t\right) \leq M\left(x_{m}, x_{n}, t\right)$, therefore $\left\{\mathrm{x}_{\mathrm{n}}\right\}$ is also a Cauchy sequence with respect to $\mathrm{M}$. By completeness of

$\left(\mathrm{X}, \mathrm{M},{ }^{*}\right),\left\{\mathrm{X}_{\mathrm{n}}\right\}$ converges to point $\mathrm{p}$ in $\mathrm{X}$. We claim that $p \in G$. Assume otherwise, then for each $n \in \mathrm{N}$, if $p \in X-G$ and $M\left(x_{n}, p, t\right) \leq D\left(x_{n}, X-G, t\right)$, then

$1-M\left(x_{n}, p, t\right) \geq 1-D\left(x_{n}, X-G, t\right)>0$, 
Therefore

$\frac{1}{1-D\left(x_{n}, X-G, t\right)} \geq \frac{1}{1-M\left(x_{n}, p, t\right)}$

That is

$f\left(x_{n}, t\right) \geq \frac{1}{1-M\left(x_{n}, p, t\right)}$

for each $\mathrm{t}>0$. Therefore as $n \rightarrow \infty$, for every $\mathrm{t}>0$ we get $f\left(x_{n}, t\right) \rightarrow \infty$. In particular, $f\left(x_{n}, s\right) \rightarrow \infty$ .On the other hand, $M\left(f\left(x_{n}, s\right), f\left(x_{m}, s\right), t\right) \geq m\left(x_{m}, x_{n}, t\right)$, for every $m, n \in \mathrm{N}$, that is $\left\{f\left(x_{n}, s\right)\right\}$ is an F-bounded sequence. This contradiction shows that $p \in G$. Hence $\left\{\mathrm{x}_{\mathrm{n}}\right\}$ converges to $\mathrm{p}$ with respect to $\mathrm{m}$ and $\left(\mathrm{G}, \mathrm{m},{ }^{*}\right)$ is a complete fuzzy metrizable space.

Theorem 2.6. (Alexandroff) A $G_{\delta}$ set in a complete fuzzy metric space is a topologically complete fuzzy metrizable space.

Proof. Let $\left(\mathrm{X}, \mathrm{M},{ }^{*}\right)$ be a complete fuzzy metric space and $\mathrm{G}$ be a $G_{\delta}$ set in X, that is $G=\cap_{n=1}^{\infty} G_{n}$, where each $G_{n}$ is open in X. By the above theorem, there exists a complete fuzzy metric $\mathrm{m}_{\mathrm{n}}$ on $G_{n}$ and we may assume that $\mathrm{m}_{\mathrm{n}}$ is bounded by $1-\varepsilon^{(n)}$. Let $\mathrm{H}$ be the Cartesian product $\prod_{n=1}^{\infty} G_{n}$ with the product topology. Then $\mathrm{H}$ is a complete fuzzy metrizable space. Now, for each $n \in \mathrm{N}$ let $f_{n}: G \rightarrow G_{n}$ be the inclusion map. So the evaluation map $e: G \rightarrow H$ is an embedding. Image of e is the diagonal $\Delta G$ which is a closed subset of $\mathrm{H}$ and by Corollary $1.6, \Delta G$ is complete. Thus $\Delta G$ is a complete fuzzy metrizable space and so is $\mathrm{G}$ which is homeomorphic to it.

\section{References}

[1] M.Amini and R. Saadati, Topics in fuzzy metric space, J. Fuzzy Math., 4(2003) 765-768.

[2] A. George and P.Veeramai, on some result in fuzzy metric space, fuzzy Sets and System, 64 (1994) 395-399.

[3] A. George and P. Veeramani, On some result of analysis for fuzzy metric spaces, Fuzzy Sets and Systems, 90(1997)365-368.

[4] V.Gregori and S.Romaguera, Some properties of fuzzy metric spaces, Fuzzy Sets and Systems, 115(2000)485-489.

[5] V. Gregori and S. Romaguera, On completion of fuzzy metric spaces, Fuzzy Sets and Systems, 130 (2002)399-404.

[6] V. Gregori and S. Romaguera, Characterizing completable fuzzy metric spaces, Fuzzy Sets and Systems , 144(2004) 411-420. 
[7] J. Rodrigues- Lopez, S. Ramaguera, The Hausdorff fuzzy metric on compact sets , fuzzy Sets and Systems, in press.

[8] K.D. Joshi, Introduction to General Topology, Wiely Estern, Bombay, 1991.

[9] K. Kuratowski, Topology, Academic press, New York, 1966.

[10] R.E.Megginson., An Introduction to Banach space theory, Springer - Verlag, New York, 1998.

[11] B. Schewizer and A. Sklar, Satistical metric spaces, Pacific J. Math., 10(1960) 314-334.

[12] L.A. Zadeh, Fuzzy sets, Inform. And control, 8(1965) 338-353. 